\title{
KONSEKUTIVNO PREVOĐENJE U AKADEMSKOM KONTEKSTU: ISKUSTVO SA SRBOFONIM STUDENTIMA ITALIJANSKOG KAO LS
}

S obzirom na sve veću potražnju kompetentnih usmenih prevodilaca, tendenciju uslovljenu jezičkom obrazovnom politikom mnogih zemalja i tržišnom dinamikom Evropske unije, otvaraju se višestruke mogućnosti ali i potrebe za dodatnom obukom studenata koji strani jezik uče na univerzitetu. Takva obuka bi, u našem slučaju, predstavljala pragmatičnu komponentu, odnosno dopunu postojećim teorijskim i interdisciplinarnim znanjima iz jezika, književnosti i kulture, koja se stiču tokom četvorogodišnjih studija u okviru osnovnog akademskog programa na Filološkom fakultetu Univerziteta u Beogradu.

U nameri da osposobimo studente za predstojeće zahteve tržišta rada, organizovali smo, u okviru jednogodišnjih master studija na Katedri za italijanski jezik i književnost, početni kurs konsekutivnog prevođenja. U radu koji sledi predstavićemo istorijski kontekst u kome se razvija konsekutivno prevođenje, daćemo kratak pregled naučnih istraživanja iz ove oblasti i ilustrovati nastavni pristup putem koga smo studentima italijanskog kao stranog jezika (LS) po prvi put predstavili i približili ovaj oblik usmenog prevođenja.

Ključne reči: konsekutivno prevođenje, univerzitetska nastava, metodika nastave, italijanski jezik.

\section{Uvod}

Nedostatak uređaja za beleženje usmenog govora kao i viševekovna tendencija naučnika da u okviru traduktologije na prvom mestu proučavaju pisano prevođenje (staro koliko i sama književnost), uslovili su nepostojanje proverenih istorijskih podataka o počecima usmenog prevođenja. Ipak, sigurno je da ta disciplina postoji koliko i jezik, i to onaj usmeni koji

drljevic@gmail.com 
je dugo vremena egzistirao pre pojave prve pisane reči (Bidoli, 1999: 4; Pavlović, 2010: 11).

Kako pisano tako, po našem mišljenju, još više usmeno prevođenje proizilaze ponajviše iz potrebe čoveka da komunicira. Ova potreba postala je tokom istorije posebno izražena usled migracija i razvoja trgovine. Brojni autori ove oblasti istraživanja jezika i jezičke upotrebe kao jedan od najstarije zabeleženih primera pojave usmenog prevođenja navode stari Egipat u kome su 3000. p.n.e. stanovnici granične teritorije između Nubije i Egipta često korišćeni, upravo zbog svoje dvojezičnosti, u svrhu usmenog prevođenja (Kurz, 1985: 213-218). Neke druge razvijene civilizacije prehrišćanske ere nisu imale toliko poštovanja prema prevodiocima. U staroj Grčkoj je vladalo mišljenje da potčinjeni narodi moraju naučiti grčki jezik koji je smatran univerzalnim jezikom komunikacije tog vremena. U starom Rimu je poznavanje više jezika bilo česta pojava, a posebno je bilo rašireno poznavanje grčkog jezika. I pored toga, na skupovima Senata postojali su zvanični prevodioci koje je rimska država plaćala da po službenoj dužnosti prevode na latinski jezik (Bidoli, 1999: 5). Sa pojavom hrišćanstva jača i prevođenje i to u cilju širenja nove religije, što dostiže svoj vrhunac u srednjem veku. Tada se pojavljuju i prve organizovane grupe prevodilaca koji počinju da zauzimaju istaknuto mesto najpre na istočnim dvorovima, na kojima se i pre XII veka beleži prisustvo tzv. dragomana, a potom i na mnogim dvorovima zapadne Evrope (Pavlović, 2010: 13). Počev od perioda poznog srednjeg veka uvećava se broj pisanih svedočanstava o usmenim prevodiocima čija se imena najvećim delom vezuju za osvajanja Novog Sveta, vojne ili naučne ekspedicije ali i državne i diplomatske poslove. Još uvek, doduše, nema reči o profesiji prevodioca, već se ponajviše ovakvo komuniciranje definisalo kao veština, koju su često posedovali pripadnici najrazličitijih slojeva društva. Za razliku od pisanog (književnog ili filozofskog) prevođenja, usmeno prevođenje čak do XX veka nije bilo predmet naučnog izučavanja. Smatralo se da nastaje kao produkt trenutnog zahteva u uslovima neke komunikativne situacije, prekida i produžuje direktnu komunikaciju, padajući u zaborav čim ispuni svoju osnovnu funkciju - prenošenje poruke (Bidoli, 1999: 7-10; Riccardi, 2003: 23-24).

Prvi usmeni prevodioci koji su se krajem XIX i početkom XX veka ovim poslom bavili profesionalno nisu još uvek bili formalno obučavani 
za ovaj poziv, već se radilo o izuzetno obrazovanim i uglednim članovima društva, poliglotama, koji su se istovremeno nalazili na različitim visokim funkcijama: ambasadori, lingvisti, direktori instituta, filozofi (Garzone, Santulli i dr., 1992: 16-17; Riccardi, 2003: 102).

Zvaničnim početkom konsekutivnog prevođenja, u današnjem smislu reči, tokom koga prevodilac prevodi tek pošto govornik završi određenu jezičku celinu, smatra se Mirovna konferencija u Parizu 1919. Tom prilikom su parovi prevodilaca, najvećim delom iz redova vojske, konsekutivno prevodili sa i na dva radna jezika: francuski i engleski. Po prvi put engleski jezik, uz francuski, dobija status zvaničnog jezika diplomatskih pregovora; prvi put se organizuje višejezični skup; prvi put usmeni prevodilac dobija ulogu jezičkog i kulturnog medijatora (Baigurri-Jalon, 2005: 987).

Godine pre i posle drugog svetskog rata obeležene su postepenim tehnološkim i tehničkim razvojem koji će omogućiti prelazak na simultano prevođenje. Ova forma prevođenja je do današnjih dana unapredila, pojednostavila i pre svega ubrzala proces usmenog prevođenja, posebno kada je reč o velikim međunarodnim vešejezičnim skupovima. Ono što treba naglasiti, i čime otvaramo naredno poglavlje našeg rada, jeste da konsekutivno prevođenje, osim što predstavlja ,najrašireniji vid usmenog prevođenja“ (Pavlović, 2010: 57), ujedno čini i osnovu, mentalnu pripremu i neophodnu jezičku vežbu za dalje usavršavanje i savladavanje tehnike simultanog prevođenja (Palazzi, 1999: 26-27).

\section{Konsekutivno prevođenje - osnovne smernice}

Kao što smo pomenuli u uvodnom delu rada, za razliku od simultanog prevođenja koje se organizuje za potrebe višejezičnih skupova, uz obavezno angažovanje stručnog tehničkog kadra i opreme, konsekutivno prevođenje ima široku primenu u uslovima usmenog prevođenja sa i na dva radna jezika. U izuzetnim prilikama, kada intervencije govornika ne prelaze nekoliko minuta izlaganja, konsekutivno prevođenje se može upotrebiti i za više od dva jezika. Ovaj oblik usmenog prevođenja najviše se koristi prilikom zvaničnih susreta delegacija, konferencija za štampu, intervjua, ceremonija inauguracije, sastanaka političkih ili ekonomskih radnih grupa, poseta lokalnim, regionalnim ili državnim institucijama, bilateralnim sastancima, pregovorima između preduzeća ali i rezervisanim sastancima iza zatvorenih vrata (Riccardi, 2003: 110-111; Pavlović, 2010: 56). 
Prvu teorijsku osnovu, načine funkcionisanja i metodologiju obuke profesionalnih konsekutivnih prevodilaca postavili su pedesetih godina prošlog veka, na osnovu sopstvenog posleratnog radnog iskustva u vodećim međunarodnim institucijama, Žan Herbert (Jean Herbert, 1952) i Žan-Fransoa Rozan (Jean-Francois Rozan, 1956). Na njihov rad će se do devedesetih godina istog veka sistematski nadovezivati brojni drugi autori, na prvom mestu Selesković (Seleskovitch, 1986), Černov (Chernov, 1979), Arkaini (Arcaini, 1986), i Žile (Gile, 1995). Neki od njih su (npr. Gile) u proučavanju procesa usmenog prevođenja zauzeli interdisciplinarni pristup, uključujući u svoje studije saznanja iz drugih, srodnih, nauka kao što su psiholingvistika ili kognitivna psihologija (Pochhacker, 2009: 130-131; Riccardi, 2003: 126-127).

Svi autori se slažu u mišljenju da se konsekutivno prevođenje sastoji od nekoliko faza tokom kojih se odvija pre svega mentalna a tek potom međujezička obrada podataka (Giambagli, 1999: 232). Ove faze predstavljaju, samo naizgled, hronološki sled. U praksi se one prepliću ili dešavaju gotovo istovremeno.

Tokom prve, receptivne, faze dešava se nekoliko međusobno uslovljenih podfaza. Prevodilac tokom aktivnosti pažljivog slušanja dobija određenu količinu informacija kojoj, tokom mentalnog procesiranja, mora pristupiti analitički kako bi shvatio i razumeo njen smisao. Dakle, u ovoj prvoj fazi, o kojoj neki autori (Palazzi, 1999: 29-30) govore kao o fazi razotkrivanja ,namere“ govornika, dužnost prevodioca jeste da razume smisao poruke, udaljavajući se od striktno jezika, odnosno od pojedinačnih reči. U ovoj fazi značajnu ulogu igra i kratkoročno pamćenje i niz specifičnih (kulturnih) kompetencija od kojih će, u velikoj meri, zavisiti ostale faze (Garzone, Santulli i dr., 1992: 34-36).

U drugoj fazi, koja prema mnogim autorima (Giambagli, 1999: 232244; Palazzi, 1999: 33; Garzone, Santulli i dr., 1992: 43) predstavlja pravu tehničku stranu konsekutivnog prevođenja, prevodilac koristi sistem bele$\check{z} a k a$ koje mu, tokom treće, produktivne, faze mogu biti od koristi, pre svega kao dopuna ili podrška dugoročnom pamćenju. Iako se u okviru brojnih priznatih škola metodika učenja konsekutivnog prevođenja najvećim delom zasniva upravo na učenju i savladavanju sistema beleženja i iako bismo, proučavajući literaturu koja se bavi ovom fazom, mogli opisati neka njegova pravila i zakonitosti, ostaje činjenica da beleženje jeste individual- 
KONSEKUTIVNO PREVOĐENJE U AKADEMSKOM KONTEKSTU:

ISKUSTVO SA SRBOFONIM STUDENTIMA

ni izraz svakog pojedinačnog prevodioca. Ovaj složeni ,jezičko-pojmovni kod" (Russo, 1999: 245) sastoji se od jezičkih elemenata (često skraćenica i akronima), simbola, crteža i najmaštovitijih, personalizovanih, grafičkih rešenja i nužno se razvija kroz dugu praksu (Giambagli, 1999: 242).

Uspeh produktivne faze, tokom koje prevodilac uz tek delimičnu pomoć beležaka, koje tumači, prenosi poruku na ciljni jezik, zavisiće u najvećoj meri od prve faze (pre svega od toga kako je razumeo smisao sadržaja), pamćenja, specifičnih i opštih kulturnih kompetencija i niza drugih faktora: analitičkih veština (uključujući i prevodilačke strategije rezimiranja, preskakanja, parafraziranja), prosemičkih i kinezičkih elemenata koje prate svaki usmeni diskurs i deo su šire komunikativne kompetencije. Konsekutivni prevod, usled svojih očiglednih tehničkih nedostataka, ne sme biti duži od izlaganja govornika. Prema nekim autorima (Garzone, Santulli i dr., 1992: 21) prevodilac na raspolaganju ima 3/4 ili 2/3 vremena trajanja originalnog teksta.

Možemo da zaključimo da je konsekutivno prevođenje, kao i ostale vrste usmenog ali i pisanog prevođenja, složen proces koji ne predstavlja čisto jezički čin. Mišljenja smo da je u definisanju konsekutivnog prevođenja najprikladnije prihvatiti komunikacijski pristup prema kome prevođenje predstavlja prenošenje poruke koja bi imala jednak efekat u oba jezika, obe kulture, odnosno i na pošiljaoca i na primaoca te poruke (Sibinović, 1990: 112).

\section{Filološke studije - od glotodidaktičkog pisanog prevođenja do obrazovanja stručnih prevodilaca}

Sve do 2006 godine, kada je na Filološkom fakultetu Univerziteta u Beogradu izvršena reforma visokog školstva prihvatanjem principa Bolonjske deklaracije, pisano prevođenje je predstavljalo jednu od osnovnih vežbi za učenje stranih jezika, proveravanje znanja i objašnjavanje novih jezičkih sadržaja. Ovakva vrsta prevođenja naziva se još i školskim, predagoškim ili glotodidaktičkim prevođenjem i u okviru gramatičko-prevodnog metoda bila je dominantno sredstvo u nastavi stranih jezika na filološkim studijama. Međutim, ne treba zaboraviti da pisano prevođenje u okviru filoloških studija, poštujući filološki pristup prema kome prevođenje predstavlja negovanje lepe književnosti i očuvanje umetničke vrednosti izvor- 
nog teksta, veoma često jeste i cilj jezičkog obrazovanja za veliki broj studenata. Naime, pored učenja jezika, studenti prirodno otkrivaju i složen prevodilački proces, neminovno stičući veštine neophodne za razvoj i dostizanje prevodilačke kompetencije (Piletić, 2013: 5-8). Iako filološke studije ne treba mešati sa univerzitetskim studijama koje za cilj imaju obrazovanje stručnih prevodilaca ${ }^{1}$, smatramo da se, u okviru reformisane univerzitetske nastave stranih jezika, koja uključuje široku interdisciplinarnost u svoj program, i usled zahteva aktuelnog tržišta rada kojima se prednost daje kadru sa praktičnim i primenjivim znanjima, otvara dovoljno prostora za nastavu i usavršavanje dodatnih segmenata u pisanom i usmenom prevođenju. Sa tom namerom smo, u školskoj 2014/2015. godini, u okviru master studija na Katedri za italijanski jezik i književnost Filološkog fakulteta u Beogradu, ponudili kurs konsekutivnog prevođenja na predmetu Jezik struke.

\subsection{Metodika nastave konsekutivnog prevođenja - iskustva sa srbofonim studentima italijanskog kao LS}

Predmet Jezik struke na petoj godini studija pokrenut je na Katedri za italijanski jezik i književnost školske 2011/2012. godine sa ciljem da se kroz teorijska predavanja, jezičke vežbe, prezentacije i zadatak izrade glosara studenti upoznaju sa pojmom, definicijama, osnovnim osobinama i načinima funkcionisanja jezika struke. Od školske 2014/2015. godine u postojeći program, koji podrazumeva i pisano prevođenje tekstova iz stručnih oblasti ${ }^{2}$ po izboru studenata, uključeni su i časovi jezičkih vežbanja usmenog (konsekutivnog) prevođenja. Tokom nepuna dva mes-

1 Višedecenijsku tradiciju u univerzitetskoj nastavi pisanog i usmenog prevođenja kojom se obučavaju profesionalni prevodioci imaju fakulteti u Trstu (Scuola Superiore di lingue Moderne per Interpreti e Traduttori) i Forliju (Scuola Superiore di lingue Moderne per Interpreti e Traduttori degli Studi di Bologna).

2 Studenti odabiru tekstove iz sledećih stručnih oblasti: ekonomija, elektro i mašinska industrija, energetika, hemijska i naftna industrija, telekomunikacije i informatika, institucije Evropske unije, prevođenje u evropskoj uniiji, vojna industrija i vojni savezi, finansije i poreski sistem, međunarodne finansijke institucije, investicije i akcionarstvo, političke partije, izbori, društveno uređenje, poljoprivreda i prehrambena industrija, ljudska prava, NGO, industrija lepote, preventivna i zdravstvena zastita, socijalna zastita, trgovina i marketing, obrazovanje, crna hronika, kriminal, sudska hronika. 
KONSEKUTIVNO PREVOĐENJE U AKADEMSKOM KONTEKSTU: ISKUSTVO SA SRBOFONIM STUDENTIMA

eca, koliko su trajali časovi, sa nedeljnim fondom od dva časa, osmislili smo i predstavili studentima brojne teorijske i praktične segmente konsekutivnog prevođenja.

Upoznavanje studenata sa teorijskim osnovama usmenog prevođenja prošao je kroz nekoliko nastavnih faza:

1. Predavanje o suštinskim razlikama između pisanog i usmenog prevođenja: faze u prevođenju, korišćenje rečnika i priručnika, shvatanje greške, poimanje i manipulacija pisanim i usmenim tekstom, stil, sintaksa, korišćenje prosemičkih i kinezičkih neverbalnih elemenata.

2. Definisanje različitih vrsta usmenog prevođenja: konsekutivno prevođenje, prevođenje na bilateralnim sastancima, šišotaž (fr. chuchotage), simultano prevođenje.

3. Predavanje o fazama konsekutivnog prevođenja: recepcija (veština slušanja, razumevanje, kratkoročna memorija i načini vežbanja memorije); teorija beleženja (struktura i organizacija beležaka na papiru, prikaz mogućih jezičkih, simboličkih, grafičkih i sintaksičkih rešenja (Russo, 1999: 262-272), prikaz video materijala ${ }^{3}$ ); produkcija (jezičko izražavanje, ton i registar, prevodilačke strategije, ispravljanje grešaka, uticaj i pravila nejezičkog izražavanja).

4. Definisanje figure usmenog prevodioca (jezičke i kulturne kompetencije, analitičke veštine, osobine).

Časovi vežbanja usmenog prevođenja koncipirani su u tri nastavne faze: prevođenje bez beleženja teksta, prevođenje sa selektivnim beleženjem i prevođenje sa beleženjem. Pre slušanja teksta, koji je trebalo prevesti, studentima bismo ukratko predstavili temu i ključne reči ukoliko se radilo o stručnim tekstovima.

U prvoj (pripremnoj) fazi studentima je predočena važnost razvoja veštine aktivnog slušanja i vežbanja memorije. Prva grupa vežbi sastojala se u prepričavanju usmenih tekstova, prvo na maternjem a potom na stranom, italijanskom, jeziku. Već u ovoj fazi naglašeni su osnovni principi i strategije konsekutivnog prevođenja: razumevanje smisla, prenošenje poruke, upotreba elipse, načini kompenzovanja nepoznate leksike. Druga

3 Prikazani video materijal predstavlja primer beleženja za engleski, španski i italijanski jezik i preuzet je sa sledećih internet adresa: https:/www.youtube.com/ watch?v=Cz3fjAX5Meg; https://www.youtube.com/watch?v=gG65XDLIeEU; https:/www.youtube.com/watch?v=otRzvCqYgDQ. 
grupa vežbi imala je za cilj usmeno prevođenje kraćih tematskih celina bez beleženja. Studenti su prvo prevodili tekstove na L1 a zatim na LS. U narednoj tabeli dajemo primer delova prevođenih tekstova:

1.

Kao što se može zaključiti iz tabele izabrani tekstovi ne sadrže specifične informacije, činjenice ili podatake koji bi mogli „opteretiti“"pamćenje i koje bi obavezno trebalo zapisati (imena, datumi i godine, brojevi i sl.), već spadaju u domen opštih znanja i informisanosti.

Kako bismo pripremili studente za vežbe prevođenja sa beleženjem prošli smo prvo kroz vežbe prevođenja sa selektivnim beleženjem. Cilj ove nastavne faze jeste da se postepeno kod studenata razvije veština aktivnog slušanja i zapisivanja, i to na način koji neće, usled istovremenog obavljanja pomenutih aktivnosti, narušiti koncentraciju. Tekstovi su u ovoj fazi, kao i u prethodnoj, opšteg karaktera, ali sa dodatim podacima koje treba zapisati (brojevi, godine, imena i sl.). U tabeli br. 2 predstavljamo primer delova ovih tekstova:

2.

U trećoj fazi vežbanja studenti razvijaju veštinu beleženja cele poruke sa akcentom na sledećim njenim elementima: izdvajanje glavnih ideja i njihovo povezivanje na gramatičkom i logičkom planu; obavezno beleženje podataka čije bi izostavljanje ili neispravnost mogle ugroziti smisao i tačnost cele poruke (imena, funkcije, brojevi i sl.). Studentima se skreće pažnja da ne treba da beleže sve što čuju jer se u tom slučaju smanjuje aktivnost pažljivog slušanja a, samim tim, i razumevanja teksta. Tekstovi u ovoj fazi (tabela br. 3) su složenije sintaksičke i tematske strukture:

3.

U fazi evaluacije usmenog prevođenja, imajući u vidu ograničen broj časova, usmeno se prevode tekstovi do 200 reči dužine. Tekstovi se čitaju iz dva dela sa maksimalnom dužinom trajanja do 2 minuta. Primetili smo da studenti najviše poteškoća imaju u istovremenom slušanju i hvatanju 
KONSEKUTIVNO PREVOĐENJE U AKADEMSKOM KONTEKSTU: ISKUSTVO SA SRBOFONIM STUDENTIMA

beležaka, što ne čudi ako imamo na umu da se stvaranje navika i refleksa u konsekutivi razvija kroz dugu praksu. Zabeležili smo, takođe, i tendenciju da se faza produkcije u nekim slučajevima prekida usled nemogućnosti pronalaženja prave lekseme, što upućuje, prema našem mišljenju, na nedovoljno razvijene leksičke strategije kompenzacije, preskakanja ili parafraziranja ali i na dugogodišnju praksu u pisanom prevođenju koje nužno nameće drugačija pravila i zahteve: pronalaženje prave reči, doterivanje stila i sl. Ono što izdvajamo kao pozitivan utisak ovog početnog i uvodnog kursa konsekutivnog prevođenje jeste visok nivo motivacije studenata, postizanje zadovoljavajućeg nivoa u veštini prenošenja tačne poruke, visok nivo usmene produkcije i razumevanja teksta slušanjem.

\section{Zaključak}

U radu smo predstavili istorijski razvoj usmenog prevođenja s posebnim osvrtom na oblik konsekutivnog prevođenja i faze koje se tokom njegovog izvođenja smenjuju. Naglasili smo da se te faze prevodilačkog toka podjednako odnose i na mentalno procesiranje sadržaja i na interjezičku obradu teksta, paralelno sa kojima prevodilac treba da razvije i veštinu hvatanja beležaka čije će mu tumačenje pomoći da uspešno prevede, odnosno prenese poruku.

U nameri da približimo ovakav oblik prevođenja i pružimo makar uvid u pravila i načine funkcionisanja, organizovali smo uvodni kurs za studente master studija Katedre za italijanski jezik i književnost Filološkog fakulteta u Beogradu. Nastavnu metodiku smo koncipirali u vidu teorijskih predavanja i jezičkih vežbi koje su bile podeljene u nekoliko faza: prevođenje bez beleženja, prevođenje sa selektivnim beleženjem i prevođenje sa beleženjem celog sadržaja. Posle dvomesečnog kursa izdvajamo sledeće zaključke:

a) Kurs konsekutivnog prevođenja pozitivno utiče na motivaciju kod studenata. Smatramo da je ovakav oblik jezičke vežbe višestruko koristan jer studentima pruža priliku da testiraju znanje stranog jezika (posebno usmenu produkciju i recepciju) na potpuno nov način i otkriju još jednu veštinu, odnosno upotrebu jezika, koju će razvijati u skladu sa svojim interesovanjima.

b) Neophodno bi bilo izdvojiti veći fond časova za vežbe konsekutivnog prevođenja u cilju usavršavanja tehnike hvatanja beležaka, uvežbavanja prevodilačkih strategija i postizanja navika u smislu istovremenog izvođenja zahtevnih kognitivnih i interjezičkih aktivnosti. 
c) Studenti kroz kurs konsekutivnog prevođenja imaju priliku da spoznaju razliku između pisanog i usmenog prevođenja. Ovde pre svega mislimo na pravila koja su u vezi sa obradom i prezentovanjem usmenog teksta, vodeći računa o parametrima kohezije i koherencije.

\section{Literatura}

Arcaini, E. (1986). Analisi linguistica e traduzione, le scienze del linguaggio. Bologna: Pàatron Editore.

Baigorri-Jalón, J. (2005). Conference Interpreting in the First International Labor

Conference (Washington, D. C., 1919). Meta: Translators'Journal, vol. 50, 3, 987-996.

Falbo, C., Russo, M., Straniero Sergio, F. (1999). Interpretazione simultanea e consecutiva. Problemi teorici e metodologie didattiche. Milano: Editore Ulrico Hoepli.

Garzone, G., Santulli, F., Damiani, D. (1992). La “Terza lingua”. Metodo di stesura degli appunti e traduzione consecutiva. Milano: Cisalpino. Istituto Editoriale Universitario.

Gile, D. (1995). Basic Concepts and Models for Interpreter and Translator Training. Amsterdam, Philadelphia: John Benjamins.

Herbert, J. (1952). Manuel de l'interprète. Comment on devient interprète de confèrence. Genève: Librairie de l'Université Georg.

Kurz, I. (1985). The rock tombs of the princes of Elephantine, earliest references to interpretation in Pharaonic Egypt. Babel, 31(4), 213-218.

Pavlović, V. (2010). O prevodilaštvu i prevodiocima. Beograd: Skripta.

Piletić, D. (2013). Prevođenje na univerzitetskim studijama italijanskog jezika i književnosti: od školskog prevoda ka sticanju prevodilačke kompetencije (neobjavljena doktorska disertacija). Filozofski fakultet Univerziteta Crne Gore.

Riccardi,A. (2003). Dalla traduzione all 'interpretazione. Studi d'interpretazione simultanea. Milano: Edizioni Universitarie di Lettere Economia Diritto.

Rozan, J-F. (1956). La prise de notes en interprétation consécutive. Genève: Librairie de l'Université Georg.

Seleskovitch, D., Lederer, M. (1986). Interpréter pour traduire. Paris: Didier Erudition.

Sibinović, M. (1990). Novi original: uvod u prevođenje. Beograd: Naučna knjiga. 


\section{Prilozi:}

\begin{tabular}{|l|l|}
\hline LS $\rightarrow$ L1 & L1 $\rightarrow$ LS \\
\hline "Per mantenere la pelle sana e prevenire & "Kada ste na redukovanom načinu \\
le pieghe della pelle la prima cosa da fare & ishrane, nije važno samo šta jedete, \\
è mangiare sano. Le verdure e la frutta & već i šta pijete, upozoravaju nutri- \\
danno le sostanze nutritive giuste per la & cionisti. Voćni sokovi nisu najbolji \\
pelle. Senza una dieta sana la pelle non & izbor ako želite da smršate, kao ni ve- \\
sarà mai sana e bella". & $\begin{array}{l}\text { like količine kafe i napitaka bogatih } \\
\text { kofeinom". }\end{array}$ \\
\hline
\end{tabular}

Tabela 1: Primer dela teksta za konsekutivno prevođenje bez beleženja

\begin{tabular}{|l|l|}
\hline LS $\rightarrow$ L1 & L1 $\rightarrow$ LS \\
\hline "Sono 1000 i prodotti del Made in Italy & "Samo na Univerzitetu u Beogradu \\
che si attestano i primi posti nell'export & krajem osamdesetih godina dvade- \\
mondiale, mostrando, anche in piena & setog veka bilo je oko 20000 stranih \\
crisi, un'Italia che compete sui mercati & studenata. Uglavnom su dolazili mladi \\
globali e crea un attivo di 183 miliardi di & sa Bliskog istoka i iz Severne Afrike. \\
dollari con un totale di 946 prodotti clas- & Danas, na najstarijem srpskom univer- \\
sificati primi, secondi e terzi nel com- & zitetu studira oko 1700 stranih stude- \\
mercio mondiale". & $\begin{array}{l}\text { nata, koji najviše dolaze preko stu- } \\
\text { dentskih razmena". }\end{array}$ \\
\hline
\end{tabular}

Tabela 2: Primer dela teksta za konsekutivno prevođenje uz selektivno beleženje

\begin{tabular}{|l|l|}
\hline LS $\rightarrow$ L1 & L1 $\rightarrow$ LS \\
\hline "L'Italia è il paese del vino. Quello che & "Te, 1868 godine, kada je osnovano \\
fino ad oggi sembrava essere un dato di & Narodno pozorište u Beogradu, Srbija \\
fatto circa il nostro Paese, rischia ora di & je jedva imala nešto preko milion i \\
essere messo fortemente in discussio- & dve stotine hiljada stanovnika. Celok- \\
ne. Nel Bel Paese, infatti, i consumi del & upna srpska prosveta raspolagala je \\
"nettare degli dei" sono in fortissimo & sa 423 učitelja muških i 54 učiteljice \\
calo. Lo rivela la Coldiretti in occasione & ženskih osnovnih škola. Beograd je \\
del Vinitaly, che apre domani a Verona. & tek prešao cifru od 25000 žitelja koji \\
L'associazione quantifica in 22,6 milio- & su stanovali u 3444 kuće". \\
ni di ettolitri il consumo di vino in Ita- & \\
lia nel 2012 con un calo del 2\% rispetto & \\
all'anno precedente". & \\
\hline
\end{tabular}

Tabela 3: Primer dela teksta za konsekutivno prevođenje uz beleženje 
Jelena R. Drljević

Jelena R. Drljević

\section{Riassunto}

\section{INTERPRETAZIONE CONSECUTIVA NEL CONTESTO CCADEMICO: ESPERIENZA CON GLI STUDENTI SERBOFONI D'ITALIANO LS}

Il presente contributo è stato concepito con lo scopo di illustrare il corso introduttivo di interpretazione consecutiva che abbiamo realizzato al Dipartimento di lingua e letteratura italiana della Facoltà di Filologia a Belgrado. Abbiamo avvicinato gli studenti del quinto anno di studi a varie fasi dell'interpretazione consecutiva e gli abbiamo fatto notare le differenze teoriche e pratiche tra la traduzione e l'interpretazione. Alla fine del corso abbiamo evidenziato alcuni punti rilevanti: il corso d'interpretazione consecutiva influisce positivamente sulla motivazione degli studenti, dà la possibilità di verificare ulteriormente la conoscenza di lingua straniera, favorisce l'esercizio linguistico concernente la manipolazione del testo orale e il rafforzamento delle abilità linguistiche orali. 